\title{
EDITORIAL
}

\section{Whither microbial sciences?}

\author{
Charles Dorman, professor of microbiology at the University of Dublin, Trinity College, \\ discusses some of the insights gained from a recent review of microbial sciences in the \\ United Kingdom.
}

Readers of Nature Reviews Microbiology will have their own opinions about the current state and future prospects of the microbial sciences. Informal discussions with colleagues based in the United Kingdom (UK) might lead one to conclude that the discipline there is under pressure. However, some interesting, positive messages emerged from a 2006 review (http://www.bbsrc.ac.uk/about/pub/ reports/06_sept_microbialreview.html) of microbial sciences in the UK that was chaired by the author and commissioned by the Biotechnology and Biological Sciences Research Council (BBSRC), the main funding body for non-medical microbiology in the UK.

The review committee found that microbiology is a broad subject that historically has been strong in the UK and is generally in a robust state today. However, we also concluded that there is no room for complacency. The discipline faces significant challenges, many of which are associated with the changes that are afoot in the biological sciences and the wider world. Technological innovations have improved our ability to obtain new information about microbial systems, their interactions with one another and their relationships with the wider environment. This success has resulted in bottlenecks as we attempt to integrate this new information into our ever-expanding picture of the natural microbial world. Such bottlenecks are partly technical and partly intellectual. In the short term, the technical problems will probably be easier to address; it is the perceived deficits in human capital that will be more challenging.

The microbiological research assets of the UK are distributed across four nations, in universities, research institutes and commercial companies. BBSRC is proposing to address this geographical spread by encouraging cooperative approaches to national research across multiple sites through the formation of strategic networks. BBSRC-funded research institutes are also involved in discussions to ensure that their important (and frequently unique) contributions to microbial sciences continue to be used to the greatest extent possible. Microbial research in the UK is supported by a range of funding agencies, including research councils, government departments and charities. Inter-agency communication is essential if we are to avoid the emergence of research gaps, and it is pleasing to see that this is underway at the highest levels.
Like every branch of science, microbiology must recruit talented individuals in the face of stiff competition from other career options. Learned societies such as the Society for General Microbiology (SGM) and the Society for Applied Microbiology (SfAM) have key roles to play in the recruitment process through their conferences, publications and outreach programmes. Funding agencies also have a vital role by providing structures for career development, in partnership with higher education institutes and industry. A two-way interaction between funding bodies and learned societies has the potential to work to the benefit of microbiology, although this must be managed carefully so that the independent position of the societies is never compromised.

In science, progress is reflected not only in the acquisition of knowledge but also in novel practical outputs. The public must receive - and be seen to receive - value for the money that it invests in science. The application of microbiological knowledge is just as deserving of investment of intellectual talent as the efforts to generate this knowledge in the first place, and the evidence indicating that the brightest young biomedical scientists are avoiding careers in industry is a cause for concern (http://www.acmedsci.ac.uk/p48prid31.html). BBSRC is already making strenuous efforts to ensure that the science it supports finds useful applications, and this is to be applauded. However, there is some way to go before we in the research community erase the impression that the science that is pursued in industry is somehow in a lower class compared to the science that is carried out in academia or in research institutes.

Of course BBSRC, in addition to responding to change is itself also subject to change, and at the time of writing is in the process of appointing a new Chief Executive as well as reviewing the priorities and structures of its funding panels, including those that are relevant to microbiology. In addition, the outcome of the UK Government's Comprehensive Spending Review (http://www.hm-treasury.gov.uk/spending_review/ spend_index.cfm) will have a significant impact on the ability of BBSRC to implement the recommendations of the Microbial Science Review. It will be interesting to see how all of these developments influence UK microbial science in the near future. 